\title{
ballot
}

\section{Identificação eleitoral biométrica no Brasilł retorno ao mecanismo panóptico ${ }^{1}$}

Eugênia Nogueira do Rêgo Monteiro Villa (Unisinos, Brasil)

eugenianogueiravilla@yahoo.com.br

Secretaria de Segurança Pública,

Rua Tersandro Paz Piçarra 64015015

Teresina, PI - Brasil

Geórgia Ferreira Martins Nunes (Unisinos, Brasil)

georgianunesadv@hotmail.com

Margarete de Castro Coelho (Unisinos, Brasil)

margaretecoelho@uol.com.br

1. Expressão cunhada por Michel Foucault para indicar vigilância sobre indivíduos situados no interior de uma máquina de poder. (FOUCAULT, 2008, p.87). 


\title{
Resumo
}

O estudo imbrica o sistema criminal com o sistema eleitoral brasileiro, analisando os efeitos do recadastramento biométrico de eleitores e sua repercussão no sistema de política criminal, na medida em que funciona como mais um dispositivo de controle social, não apenas no campo da Justiça Eleitoral, mas, e especialmente, no campo criminal, a partir do momento em que os dados coletados de forma cogente pela Justiça Eleitoral são submetidos ao Sistema Automatizado de Identificação de Impressões Digitais - AFIS, com sede na Polícia Federal. Assim, amplia-se a via da identificação criminal imposta pelo Estado ao cidadão brasileiro sem que este ao menos se aperceba estar produzindo, antecipadamente, provas contra si mesmo. Discute-se, pois, a questão a partir de três pontos centrais: o primeiro percorre a ideia de poder e controle social com enfoque na biopolítica, disciplinamento dos corpos e panoptismo. O segundo momento trata da discussão sobre a atual política criminal baseada na expansão do Direito Penal e, finalmente, o terceiro capítulo retoma a discussão anterior sob o enfoque do recadastramento eleitoral biométrico, analisando-o na perspectiva do controle social criminal. Para o estudo, são utilizados aportes teóricos de FOUCAULT (2009), RIPOLLÉS (2007) e CALLEGARI (2010).

Palavras-chave: Cadastro Biométrico- eleitoral. Controle social. Panoptismo.

\begin{abstract}
The study criminal system overlaps with the Brazilian electoral system, analyzing the effects of re-registration of voters in the Electoral Court through the biometric examination and its impact on criminal policy system, working more as a device of social control not only in the field of Justice election, but especially in the criminal field, from the moment that the data collected by the Electoral Court cogent form is linked to the Automated Identification System Fingerprint - AFIS , established the Federal Police, thus expanding the route identification imposed by state criminal the Brazilian citizen without the same being aware of being producing evidence against yourself in advance. Discusses the issue from three central points: the first runs the idea of power and social control with a focus on biopolitics, disciplining of bodies and panoptism. The second part deals with the discussion about the current criminal policy based on the expansion of criminal law, and, finally, the last one returns to the previous discussion under the focus of the electors relist analyzing it from the perspective of criminal social control. For the study, will be used theoretical framework of Foucault (2009), Ripollès (2007) and Callegari (2010) are used.
\end{abstract}

Keywords: Electoral and biometric registration. Social control. Panoptism. 


\section{Introdução}

A obra "1984" do escritor George Orwell (2009) é tida pela crítica como profética, tanto no que diz respeito ao processo intricado de quebra da privacidade - ao expor um desejo voyerista íntimo -, quanto ao controle do governo, que tudo observa através de câmeras - como a desafiar as mazelas do autoritarismo quando de sua publicação (1949) ou mesmo a pressagiar as máculas e vicissitudes das democracias contemporâneas.

No enredo, o "Grande Irmão" é líder máximo dos três Estados totalitários insurgentes pós-guerra mundial. $\mathrm{E}$ as circunstâncias sob as quais perpassa a história são ameaçadoras e opressivas. É o que corrobora a publicidade de cartazes espalhados pelas ruas mencionando que "O Grande Irmão está de olho em você".

De fato, o líder de "quarenta e cinco anos, de bigodão preto e feições rudemente agradáveis" está de olho em todos os cidadãos da sociedade de "1984" por meio das "teletelas". São esses instrumentos de controle espalhados por todos os lugares (públicos e privados), que transmitem, gravam, espionam e monitoram a população. Uma espécie de espelhos duplos: visto sob uma ótica, reflete; em perspectiva oposta, refrata.

Em verdade, é evidente que se trata muito mais de uma lucidez política do autor. Basta lembrar o enredo da obra acima exposto para se adentrar ao campo das aparentes coincidências em face das democracias contemporâneas. Aparentes, porque a superveniência de invasões estatais à esfera privada é um resultado óbvio diante dos Estados Democráticos de Direito emergentes de contexto totalitários. No entanto, a obviedade perpassa pelo senso comum como profecias, já que a sua percepção é própria das mentes notáveis, tais quais a de George Orwell.

Nesse cerne, ao presente estudo apetece compreender em que medida o avanço tecnológico e político retoma e amplia, em nova perspectiva, a ideia de disciplinamento de corpos e de vigilância, aquela certa feita profetizada por George Orwell. Para tanto, inicia-se a trajetória percorrendo os espaços do macropoder, o qual é traduzido na ideia da biopolítica - tecnologia utilizada pelo Estado para fins de controle da população.

Partir-se-á da concepção de uma estratégia política, uma tática geral de domínio, concebida a partir de uma base biológica associada à política. É dizer, o reconhecimento de que o ser humano constitui uma espécie humana traduz-se no primeiro instrumento de estabelecimento e manutenção do poder.

Em seguida, analisar-se-á o poder disciplinar, incidente sobre os corpos, como que a estabelecer mecanismos de vigilância. Essa apreciação tenderá à teoria do panoptismo de Michel Foucault - perspectiva de vigilância dos indivíduos, de diagnóstico do seu ser e de sua patologia própria. Além disso, perpassará pelo pensamento contemporâneo de Zygmunt Bauman, que evidencia uma ampliação dessa vigilância à medida que avançam os meios tecnológicos, deixando-nos perceber a utilização do meio imaterial da virtualidade para controlar corpos, a partir de dados pessoais obtidos muitas vezes de forma cogente, como no caso em estudo, e catalogados.

Em cerne diverso, estudar-se-á a atual política criminal, de modo a compreender a expansão da perspectiva do Direito Penal do Inimigo. É imperiosa a cristalização de um novo modelo punitivo em sede da consolidação de transformações político-criminais decisivas. Essas alterações consistem na ideologização da gestão administrativa de riscos da sociedade tecnológica pelo Direito Penal, no sentido de um discurso que não se coaduna com a necessidade da expansão da perspectiva anunciada por Günther Jakobs. 
Por conseguinte, exauridas as celeumas acerca do discurso do poder, da biopolítica, do poder disciplinar, da vigilância e do fenômeno da expansão do Direito Penal, retomar-se-á a discussão acerca dos novos instrumentos disciplinares instituídos pelo poder normatizador do Estado. É imperiosa a constatação da essência dos dispositivos de vigilância estatal, conforme se sucedem as circunstâncias do recadastramento pela Justiça Eleitoral, por intermédio da coleta de dados biométricos.

Constatar-se-á que o cadastro biométrico dos eleitores repercute no sistema de política criminal, funcionando como mais um dispositivo de controle social, não apenas em sede da Justiça Eleitoral, mas, e especialmente, no âmbito criminal. Isso porque, em razão de Acordo de Cooperação Técnica firmado entre o Tribunal Superior Eleitoral e o Ministério da Justiça, os dados coletados de forma cogente pela Justiça Eleitoral vincular-se-ão ao Sistema Automatizado de Identificação de Impressões Digitais - AFIS, sediado no Departamento de Polícia Federal.

É evidente, nessa lógica, uma ampliação concomitante da via de identificação criminal imposta pelo Estado ao cidadão brasileiro ${ }^{2}$, sem o questionamento - ou conhecimento - prévio de que se estará produzindo provas antecipadas contra si. Há, portanto, uma clara e grave infração aos direitos fundamentais no que diz respeito ao devido processo legal e de acesso à informação, além da obrigatoriedade de transparência e publicidade dos atos administrativos.

Por fim, a pesquisa desvelará uma dimensão política democrática maculada pela vigilância aparentemente invisível. E o objetivo desse controle social não é outro, senão o disciplinamento de corpos, não mais sob a consideração de um princípio do estado de inocência, mas sob a perspectiva da presunção de culpa. É dizer, todos estão sob os efeitos da vigilância estatal: não apenas o criminoso, como a priori se propunha, mas também o cidadão livre alistado ou alistável ao processo eleitoral. Há, portanto, um direcionamento político de retorno ao panóptico, bastando para este incidir que se adquira a qualidade de eleitor - ou, na linguagem constitucional, cidadão ${ }^{3}$.

\footnotetext{
2. A imposição decorre da obrigatoriedade do alistamento e voto, fixada no artigo 14 da Constituição Federal, que recepcionou o Código Eleitoral (Lei n. 4.737/65), cujo artigo 7o impede os brasileiros natos ou naturalizados, maiores de 18 anos, que não se alistarem, de realizarem atos comuns da vida civil, tais como: inscrever-se em concurso ou prova para cargo ou função pública, investir-se ou empossar-se neles; receber vencimentos, remuneração, salário ou proventos de função ou emprego público, autárquico ou para estatal, bem como fundaçóes governamentais, empresas, institutos e sociedades de qualquer natureza, mantidas ou subvencionadas pelo governo ou que exerçam serviço público delegado, correspondentes ao segundo mês subsequente ao da eleição; participar de concorrência pública ou administrativa da União, dos Estados, dos Territórios, do Distrito Federal ou dos Municípios, ou das respectivas autarquias; obter empréstimos nas autarquias, sociedades de economia mista, caixas econômicas federais ou estaduais, nos institutos e caixas de previdência social, bem como em qualquer estabelecimento de crédito mantido pelo governo, ou de cuja administração este participe, e com essas entidades celebrar contratos; obter passaporte ou carteira de identidade; renovar matrícula em estabelecimento de ensino oficial ou fiscalizado pelo governo; e praticar qualquer ato para o qual se exija quitação do serviço militar ou imposto de renda.

3. A cidadania é definida pelo exercício pleno dos direitos políticos, que, no Brasil, são regulados pela Constituição Federal em seu artigo 14, onde o sufrágio universal aponta como garantia da soberania popular. Pela norma constitucional, o alistamento eleitoral e o voto são obrigatórios para os maiores de dezoito anos, e facultativos para os analfabetos, os maiores de dezesseis e menores de dezoito anos e os maiores de setenta anos; proibindo, ainda, o alistamento eleitoral dos estrangeiros e dos brasileiros conscritos no serviço militar obrigatório.
} 


\section{A naturalidade humana}

A priori, é imprescindível demonstrar, sem pretender a exaustão do tema, o pensamento de Michel Foucault e sobre o que ele preconizava como "biopolítica". Desvelar-se-á o momento em que o ser humano deixa de ser visto como indivíduo pertencente à espécie humana e passa a integrar uma categoria denominada "população", cujo objetivo não é senão o controle e a vigilância dos indivíduos.

O âmbito da formação do Estado, a partir da conjugação dos três elementos que lhe compõe - território, população e soberania - será o ponto de partida. Com efeito, para a formação do Estado, inicialmente, fora necessário estabelecer os limites materiais sob os quais se edificaria e exerceria o poder. Além disso, impóe definir quem estava sob o jugo dessa supremacia: é dizer, quem eram os súditos.

Uma vez definidos os contornos estatais em um determinado território, passa o Estado a adotar o mecanismo do censo demográfico para conhecer os súditos. A finalidade essencial é implementar um sistema de controle social, de modo a emergir a categoria "população", ou "[...] um conjunto de elementos que, de um lado, se inserem no regime geral dos seres vivos e, de outro, apresentam uma superfície de contato para transformações autoritárias, mas refletidas e calculadas" (FOUCAULT, 2009, p. 98).

Em um primeiro momento, o conhecimento sobre esse artifício, população funda-se na ideia de um dado primevo. Uma soma de indivíduos que deviam obediência ao soberano: súditos submetidos à vontade da lei. Uma relação entre a vontade do soberano e a vontade submissa das pessoas. Compreendia-se população, portanto, como categoria estanque, voltada à fiel obediência às leis, em uma “[...] noção jurídico-política de sujeito" (FOUCAULT, 2009, p.92).

A partir do século XVIII, conforme Foucault (2009, p.92), passa-se à ideia de que a população é algo dinâmico, mercê de inúmeras variáveis, as quais percorrem desde elementos naturais - como clima, localização geográfica, riquezas naturais -, até elementos criados pelo próprio ser humano - quais sejam: a circulação de pessoas e de riquezas, a escolha da moradia, da profissão, em exemplo.

Uma vez constatada a população como algo dinâmico e constituído por múltiplos desejos, observou-se que essa dinâmica era marcada por constantes, por regularidades. No entanto, percebeu-se, ainda, que demandas aparentemente distantes da população agiam de forma benéfica ou maléfica, tais como o fomento à exportação como forma de aumentar o número de pessoas empregadas ou, ao revés, a importação, que trazia prejuízos por impossibilitar ou dificultar o aumento do número de empregados.

A partir de então, percebe-se que “[...] não se trata de obter a obediência dos súditos em relação à vontade do soberano, mas de atuar sobre coisas aparentemente distantes da população, mas que se sabe, por cálculo, análise e reflexão, que podem efetivamente atuar sobre a população". (FOUCAULT, 2009, p.94).

É essa naturalidade da população que promove "[...] uma mudança importantíssima na organização e na racionalização dos métodos de poder". (FOUCAULT, 2009, p.94). A essa irrupção da naturalidade Foucault denomina "biopoder": o ingresso do ser humano "[...] numa estratégia política, numa estratégia geral de poder" (FOUCAULT, 2009, p.3).

A população passa a ser compreendida como "[...] tudo o que vai se estender do arraigamento biológico pela espécie à superfície de contato oferecida pelo público". Nesse conceito estão inclusos suas opiniões, suas maneiras de ser e de fazer, hábitos e comportamentos, te- 
mores, preconceitos: "[...] aquilo que se age por meio da educação, das campanhas, dos convencimentos" (FOUCAULT, 2009, p.99).

A nova técnica de governo permite aliar elementos biológicos e artificiais. Esses últimos são engendrados, ou pelo Estado ou pelos próprios indivíduos, por meio do sistema econômico a regular a economia de mercado ou pelo planejamento e traçado das cidades em que as pessoas irão circular, pela construção de barragens, pontes, viadutos, pela escolha dos indivíduos sobre o lugar da moradia, do trabalho, do estudo, dentre tantos outros fatores.

Nasce, portanto, a "biopolítica": "[...] a maneira pela qual se tentou, desde o século XVIII, racionalizar os problemas propostos à prática governamental, pelos fenômenos próprios a um conjunto de seres vivos constituídos em população: saúde, higiene, natalidade, raças...." É dizer, uma política vigilante de intervenções sociais implicando na diagramação das políticas públicas voltadas à saúde, educação, segurança, habitação, desemprego e tantas quantas que proporcionem a fruição da vida pelos seres humanos. Elementos que irão servir de critério para a tomada de decisóes.

\section{A vigilância: dispositivo disciplinar}

O estudo sobre a vigilância remete ao pensamento de Michel Foucault, o qual é fundamentado no Panóptico ${ }^{4}$ de Bentham. Esse modelo arquitetural, por ele traçado, parte de um mecanismo de poder consistente na invisibilidade da observação, o qual “[...] organiza unidades espaciais que permitem ver sem parar e reconhecer imediatamente". (FOUCAULT, 2012, p.190).

Preleciona Foucault (2012, p.192) que "[...] o poder externo [...] tende ao incorpóreo: e quanto mais se aproxima desse limite, mais esses efeitos são constantes, profundos, adquiridos em caráter definitivo e continuamente recomeçados: vitória perpétua que [...] está sempre decidida por antecipação". Ainda conforme o mesmo autor (FOUCAULT, 2012, p.195), "o esquema panóptico é um intensificador para qualquer aparelho de poder: assegura sua economia (em material, em pessoal, em tempo); assegura sua eficácia por seu caráter preventivo, seu funcionamento contínuo e seus mecanismos automáticos".

O panóptico se ajusta aos processos de controle imprescindível. Adentra sutilmente às estruturas de poder para potencializar sua eficácia e disciplinar os corpos. "Bentham sonha fazer delas uma rede de dispositivos que estariam em toda parte e sempre alertas, percorrendo a sociedade sem lacuna nem interrupção" (FOUCAULT, 2012, p.197).

Embora o panóptico tenha sido pensado numa perspectiva institucional fechada, de disciplina de exceção, seus postulados se direcionam a uma vigilância generalizada, flexível, transferível e adaptável. Exercer esse poder significa "[...] adquirir o instrumento para uma vigilância permanente, exaustiva, onipresente, capaz de tornar tudo visível, mas com a condição de se tornar ela mesma invisível". (FOUCAULT, 2012, p.202).

Dessa forma, a disciplina não se restringe a determinada instituição. É um instrumento, uma técnica ou uma tecnologia de poder à disposição das organizaçóes que almejam reforçar

4. O modelo de Bentham prevê“ "...] na periferia uma construção em anel; no centro uma torre: esta é vazada de largas janelas que se abrem sobre a face interna do anel", de modo que se dissocia "[...] o par ver-ser-visto: no anel periférico, se é totalmente visto, sem nunca ver; na torre central, vê-se tudo, sem nunca ser visto". (FOUCAULT, 2012, pp.191 e 192). 
seus mecanismos de poder, de modo a permitir alcançar os mais longínquos espaços de relações de poder.

Foucault (2012, p.210) menciona que "por regular e institucional que seja, a disciplina, em seu mecanismo, é um 'contradireito'. E se o juridismo universal da sociedade moderna parece fixar limites ao exercício dos poderes, seu panoptismo difundido em toda parte faz funcionar, ao arrepio do direito, uma maquinaria ao mesmo tempo imensa e minúscula que sustenta, que reforça, multiplica a assimetria dos poderes e torna vãos os limites que lhe foram traçados".

Assiste-se à proliferação da então preconizada vigilância na modernidade, mas delineada por contornos suaves. Bauman (2013, p.10) denomina essa vigilância de "vigilância líquida", numa circunstância em que "velhas amarras se afrouxam à medida que fragmentos de dados pessoais obtidos para um objetivo são facilmente usados com outro fim. A vigilância se espalha de formas até então inimagináveis, [...] sem um contêiner fixo, mas sacudida pelas demandas de 'segurança' [...]".

Embora Bauman analise a vigilância líquida sob o enfoque econômico, no âmbito de uma sociedade de consumo, na qual se classifica e categoriza indivíduos a partir de dados pessoais coletados através da utilização de cartões de crédito, pode-se ampliar a discussão para outros campos alheios à categoria econômica. É evidente que, ao invés de se classificar indivíduos, tem-se em um banco de dados para fins de controle.

Esse domínio "[...] opera virtualmente, usando bases de dados em rede para canalizar fluxos de dados, especialmente sobre o que ainda está por acontecer [...]". O autor se refere ao "ban-óptico" proposto por Didier Bigo "[...] para indicar de que modo tecnologias de elaboração de perfis são usadas para determinar quem será colocado sob vigilância específica”. (BAUMAN, 2013, pp.62 e 63). O "banóptico" nasce da conjugação do termo "ban", ideia de Jean-Luc-Nancy e desenvolvida por Giorgio Agamben, com o "óptico" de Foucault, no sentido de excluir os indesejados, para incluí-los através da normalização e, assim, excluí-los para fins de controle.

Segundo Bigo (apud BAUMAN, 2013, p.63), o controle se dá por meio de instituições cujas ações "[...] convergem em relação ao fortalecimento da informática e da biometria como modos de vigilância que se concentram nos movimentos de indivíduos pelas fronteiras".

O diagrama banóptico refere-se a uma comunidade global, no plano transnacional, uma espécie de controle global de indivíduos cujo marco referencial fora as açóes terroristas perpetradas nos Estados Unidos em 2001. Deu-se relevo ao controle do deslocamento de indivíduos no plano mundial para fins de prevenção de novos atentados.

Há uma clara distinção entre o banóptico de Bigo e o panóptico de Foucault. No primeiro, a vigilância consiste em "manter a distância", de modo a extrair "[...] seus sumos vitais e energia para seu desenvolvimento da ascensão, [...] das preocupaçóes com segurança [...]". Enquanto que, no segundo, a vigilância consiste em "manter dentro", com "[...] impulso disciplinador". (BAUMAN, 2013, pp.64 e 65).

Segundo Bauman (2013, p.67), "o principal propósito do ban-óptico é garantir que o lixo seja separado do produto decente e identificado a fim de ser transferido para um depósito adequado. Uma vez lá, o pan-óptico garante que o lixo ali permaneça - de preferência, até que a biodegradação complete seu curso". Assim é que a vigilância contemporânea reinventa a ideia do diagrama proposto por Bentham. Parte-se da utilização de tecnologias que propiciam o controle de indivíduos em ambiente virtual, não idealizado por seu criador, mas que se adequa à ideia de vigilância invisível. Porém, à distância não mais material simbolizada na torre central do diagrama, senão no campo tecnológico da virtualidade. 


\section{Expansão do Direito Penal na sociedade de risco}

Atualmente, ao contrário da "lógica social" de consenso, vige a "lógica do risco", ou seja, a sociedade tem "consciência de que a tecnologia traz benefícios à vida das pessoas, mas, no entanto, também apresenta um dinamismo que foge do controle humano, impondo a 'lógica do risco"' (sic). (CALLEGARI, 2010, p.27).

A sociedade contemporânea, marcada pelo avanço tecnológico e pela globalização, apresenta riscos indeterminados. Assume dimensões que escapam a qualquer espécie de controle, de modo a inexistir contracautelas que façam frente a eles e,

Justamente em face dessa indeterminação, "os novos riscos fogem à aplicação das regras securitárias do cálculo, da estatística e da monetarização", o que significa que a eles não podem ser aplicadas as regras da causalidade e da culpa, bem como, dificilmente se poderá medir qualquer compensação ou indenização deles emanadas, "quer porque suas consequências não podem ser limitadas, quer porque o desastre atinge dimensões tão grandes que nenhuma companhia de seguros seria capaz de arcar com o custo indenizatório". (CALLEGARI, 2010, pp.30 e 31).

Na modernidade, acreditava-se serem os riscos previsíveis e, portanto, passíveis de gerenciamento e eficaz contenção. $\mathrm{Na}$ atualidade, ante o desenvolvimento tecnológico, o ser humano se vê inserido em um contexto não mais controlável. Instaura-se, assim, o medo e a insegurança na sociedade. Daí porque muitos autores afirmarem ser a atual sociedade uma sociedade de risco.

No entanto, se por um lado os atuais riscos se dão em um ambiente que escapa aos sentidos humanos, tal o caso das nanotecnologias e biotecnologias, por outro lado se vê florescer uma política criminal. E esta se apodera do discurso da sociedade de risco, de modo a imprimir um modelo securitário que se antecipa ao inter criminis com a falácia da prevenção de riscos.

O medo e a insegurança fazem com que a própria sociedade concorde com a tomada de decisões enérgicas por parte do Estado. O objetivo é uma real efetividade da lei penal a condutas especialmente graves. Isso explica porque "[...] la sociedad, en estos casos, esté dispuesta a renunciar a ciertas cotas de libertad a cambio de reforzar la seguridad"s. (RIPOLLÉS, 2007, p.183).

O reforço da segurança, segundo Ripollés (2007, p.185), traduz-se especialmente no florescimento e endurecimento de medidas cautelares prisionais e não prisionais, na majoração das penas e na maior rigidez no regime de cumprimento das sanções. E essas punições apenas são dirigidas a um determinado segmento de indivíduos classificados como perigosos, dentre os quais situam-se os que praticam violência sexual, os reincidentes e os habituais.

O mesmo autor (RIPOLLÉS, 2007, p.185) denomina o conjunto dessas medidas por "Direito da periculosidade". Seus conteúdos se espraiam silenciosamente no campo criminal: no direito penal e processual penal, além da fase da execução penal; sem, no entanto, reivindicar autonomia justamente para não ser questionado quanto à sua legitimidade. Na realidade, "[...] estamos ante un derecho penal que sirve a una politica criminal que busca la efectividad en el

5. “[...] a sociedade, nestes casos, está disposta a renunciar a certas cotas de liberdade em troca do reforço da segurança”. (Tradução livre). 
corto plazo, bien ejemplificada en la expresión 'barrer la delincuencia de las calles"'.6. (RIPOLLÉS, 2007, p.192).

Esse direito penal, denominado por Ripollés como sendo "modelo penal de segurança cidadâ”, abandona a ideia de ressocialização do indivíduo delinquente. Da mesma forma, afasta-se da complexidade social pluralista contemporânea no instante em que exclui pessoas para, em seguida, suscitá-las em categorias particulares e imprimir-lhes intervençóes repressivas mais severas.

RIPOLLÉS (2007, p.195) leciona, ainda, que esse modelo "[...] se há servido parasitariamente del debate sobre la sociedad del riesgo y, singularmente, de las propuestas que abogan por una modernización del derecho penal"'. Há, segundo ele, uma espécie de vampirização do direito penal clássico: emerge, de forma impetuosa e silente, um novo direito penal no interior daquele.

\section{Os sistemas de identificação de pessoasł RIC, AFIS, e cadastro biométrico-eleitoral}

Feitas essas consideraçóes, o presente estudo abordará, agora, os três principais sistemas de identificação de pessoas vigentes no Brasil: o Registro de Identidade Civil (RIC), o Sistema Automatizado de Identificação de Impressões Digitais - AFIS - e o Cadastro Biométrico Eleitoral, examinando as possibilidades e as consequências de uma integração entre eles, visto que possuem finalidades totalmente diversas.

Com efeito, o primeiro projeto, o RIC, instituído pela Lei n. 9.454/97, prevê um numero único para cada cidadão brasileiro, nato ou naturalizado, ser identificado em suas relações com a sociedade e com os organismos governamentais e privados, unificando todas as formas de identificação atualmente em vigor. Apesar de criado por lei há dezessete anos, o RIC ainda não foi implementado e somente foi regulamentado em 2010, com o Decreto n. 7.166, que criou o Sistema Nacional de Registro de Identificação Civil - SINRIC e seu comitê gestor.

O segundo, por sua vez, tem por objetivo identificar os detentores de passaporte e aqueles indiciados em procedimentos criminais para efeitos de controle de deslocamentos de pessoas, sediado no Instituto Nacional de Identificação - INI e nas Superintendências da Polícia Federal, com disponibilidade para consultoria das Secretarias de Segurança Pública dos Estados, conforme teor do Acórdão do Tribunal de Contas da União no 2.166/2013-Plenário, tendo por Relator o Ministro Augusto Sherman Cavalcanti - TC 044.496/2012-58.

Por fim, o sistema de cadastramento biométrico eleitoral está, atualmente, regulamentado pela Resolução-TSE no 23.335 de 22 de fevereiro de 2011, que disciplina os procedimentos de realização de revisões eleitorais de ofício, para atualização do cadastro eleitoral em municípios previamente selecionados pelos Regionais Eleitorais, avançando, gradativamente, até alcançar todo o território nacional.

\footnotetext{
6. [....] estamos diante de um direito penal que serve a uma política criminal que busca a efetividade à curto prazo, bem exemplificada na expressão 'barrar a delinquência das ruas".'(Tradução livre).

7. “[...] tem se servido parasitariamente do debate sobre a sociedade de risco e, de forma peculiar, das propostas que defendem a modernização do direito penal". (Tradução livre).

8. Disponível em: http://www.jusbrasil.com.br/diarios/58125588/dou-secao-1-22-08-2013-pg-105.
} 
Conforme o Tribunal Superior Eleitoral, no pleito municipal de 2012 a tecnologia alcançou 7,7 milhóes de eleitores. A meta para a terceira fase do programa: cadastrar 16 de milhóes para que cerca de 23,7 milhóes de brasileiros de todos os Estados e do Distrito Federal possam ser identificados biometricamente nas eleições gerais de 2014. No Piauí, dos 224 municípios, catorze, incluindo a capital Teresina, participaram do recadastramento biométrico que coletou dados de 736.822 eleitores, conforme quadro abaixo, fornecido pela Ouvidoria do Tribunal Regional Eleitoral do Piauí:

\section{TRIBUNAL REGIONAL ELEITORAL DO PIAUÍ SECRETARIA DE TECNOLOGIA DA INFORMAÇÃO Coordenadoria de Eleições Informatizadas}

\begin{tabular}{|l|c|c|c|}
\hline \multicolumn{1}{|c|}{ Município } & Eleitorado & \multicolumn{2}{c|}{ Revisados até $\mathbf{3 1 / 0 3 / 2 0 1 4}$} \\
\hline Teresina & 531.322 & 446.243 & $83,99 \%$ \\
\hline Parnaíba & 97.356 & 78.564 & $80,70 \%$ \\
\hline Ilha Grande & 7.325 & 5.832 & $79,62 \%$ \\
\hline Nazária & 10.123 & 7.537 & $74,45 \%$ \\
\hline Luis Correia & 23.820 & 18.915 & $79,41 \%$ \\
\hline Caj.da Praia & 5.919 & 4.924 & $83,19 \%$ \\
\hline Oeiras & 26.933 & 22.221 & $82,50 \%$ \\
\hline José de Freitas & 29.997 & 25.146 & $83,83 \%$ \\
\hline Total & 732.795 & 609.382 & $83,16 \%$ \\
\hline
\end{tabular}

\begin{tabular}{|l|c|c|c|}
\hline \multicolumn{1}{|c|}{ Município } & Eleitorado & \multicolumn{2}{c|}{$\begin{array}{c}\text { Piracuruca - 08/12/2009 } \\
\text { Piripiri - 18/03/2012 }\end{array}$} \\
\hline Piracuruca & 19.928 & 15.885 & $79,71 \%$ \\
\hline Piripiri & 43.471 & 34.806 & $80,07 \%$ \\
\hline
\end{tabular}

\begin{tabular}{|l|c|c|c|}
\hline \multicolumn{1}{|c|}{ Município } & Eleitorado & $\begin{array}{c}\text { Francisco Santos e Picos } \\
-\mathbf{1 5 / 0 2 / 2 0 1 2} \text { Floriano - } \\
\mathbf{1 6 / 0 2 / 2 0 1 2}\end{array}$ \\
\hline Floriano & 39.663 & 33.097 & $83,45 \%$ \\
\hline Francisco Santos & 7.146 & 6.059 & $84,79 \%$ \\
\hline Picos & 46.494 & 37.593 & $80,86 \%$ \\
\hline
\end{tabular}

Segundo informaçóes extraídas do sitio eletrônico do Tribunal Superior Eleitoral, "com o sistema, o Brasil poderá criar o maior banco de dados de imagens de impressão digital existente no mundo"'.

O objetivo inicial do cadastro biométrico é claro: reconhecer o eleitorado no momento do voto, para controle e fiscalização dos pleitos eleitorais, assegurando que aquela pessoa que se apresenta perante a Mesa Receptora de Votos é exatamente aquele eleitor cadastrado para compor o colégio eleitoral convocado para eleger os seus representantes.

9. Disponível em: http://www.tse.jus.br/eleicoes/biometria-e-urna-eletronica/biometria-1 
Além do evidente benefício de ordem eleitoral, conforme noticiado no site do TSE ${ }^{10}$, "a identificação biométrica dos eleitores brasileiros também servirá para outros fins". Segundo informa, a Corte Superior Eleitoral firmou acordo com o Ministério da Justiça - MJ para colaborar com o fornecimento do Cadastro da Justiça Eleitoral, que compreende mais de 140 milhões de eleitores. $\mathrm{O}$ acordo, formalizado por meio de Termo de Cooperação Técnica TSE n. 12/2010, objetiva integrar aquele Tribunal ao Sistema Nacional de Identificação Civil SINRIC (Cláusula Primeira) e prevê o repasse ao MJ dos dados biométricos colhidos - impressão digital dos dez dedos, fotografia e assinatura - acompanhados de dados biográficos dos eleitores cadastrados biometricamente, além da possibilidade de permuta de outras informações cadastrais consideradas relevantes e que constem nas respectivas bases de dados (Cláusula Terceira).

Observa-se que, em decorrência do referido acordo, os registros biométricos colhidos pela Justiça Eleitoral são recebidos no sistema AFIS para unicidade dos cadastros, com vistas à implantação do SINRIC, conforme estabelecido pelo Decreto n. 7.166/2010. Porém, o sistema AFIS tem outra finalidade, de identificação e cadastro criminal, consoante já ressaltado alhures. O gerenciamento dos dados biométricos dos eleitores e do SINRIC pelo sistema AFIS, inclusive, vem sendo objeto de questionamento até mesmo na esfera do Tribunal de Contas da União ${ }^{11}$, que ressalta, além da incapacidade operacional do AFIS para armazenar todas essas informações, mas principalmente, a impossibilidade de se unir a base de dados criminais à base de dados civis.

Ademais, a distinção entre a identificação civil e criminal tem previsão constitucional, no art. $5^{\circ}$, LVIII, o que, por si só, impossibilita a integração dos sistemas, como estabelecido, não em lei, mas em simples Termo de Cooperação entre o TSE e o Ministério da Justiça.

Soma-se a isso a grave violação do direito fundamental de acesso à informação (artigo $5^{\circ}$, $\mathrm{XIV}, \mathrm{CF} / 88$ ) consistente na falta de comunicação aos cidadãos e, especialmente, de autorização destes no momento do recadastramento, acerca da utilização dos seus dados biométricos, de caráter íntimo e personalíssimo, para outros fins não eleitorais, quiçá para fim de produção de prova datiloscópica em eventual processo criminal.

E sendo o alistamento eleitoral não apenas condição de elegibilidade, tal como previsto na Carta Magna, mas verdadeiro requisito para o exercício da plena cidadania, pois obrigatório aos brasileiros entre dezoito e setenta anos, o recadastramento

10. Disponível em: http://www.tse.jus.br/eleicoes/biometria-e-urna-eletronica/biometria-1

11. Acórdão n 2.166/2013-Plenário, Relator Min. Augusto Sherman Cavalcanti - TC 044.496/2012-

5. Disponível em http://portal2.tcu.gov.br/portal/pls/portal/docs/2618124.PDF. Consultado em 10.04.2014. 
biométrico torna-se compulsório, inevitável mesmo aos que se insurgem judicial e fundamentadamente contra sua realizaçãa ${ }^{12}$.

Além disso, sob o argumento do sigilo dos dados coletados, nem mesmo os Partidos Políticos, corpos intermediários da nossa democracia representativa, têm acesso a tais dados, mesmo que sob o argumento de se comunicarem com o eleitor, seja no momento da eleição, ou plebiscito, ou para a criação de uma nova sigla, fato que exige um apoiamento mínimo de determinado percentual de eleitores. Ou seja, nem mesmo para atividades inerentes, típicas e intimamente relacionadas com o processo eleitoral, é possível o acesso ao banco de dados dos eleitores, preservando-se-lhes, ao máximo, a intimidade. Enquanto isso, as polícias federal e civil têm amplo acesso a todos os dados que são negados aos partidos, podendo utiliza-las para fim de persecução penal.

É certo que há ocasiões que se permite aos órgãos partidários o acesso às listas nominais de eleitores em determinadas Zonas Eleitorais, mas tal informação não ultrapassa além do nome, sem constar título, endereço ou quaisquer outros dados que porventura componham os arquivos da Justiça Eleitoral.

Noutro giro, se é para que se evite fraudes quanto à identidade do eleitor, há demandas perante a Justiça Eleitoral em quantidade e frequência que indiquem tal necessidade? A Resolução n. 23.335/2011 do TSE que fixa as diretrizes para o recadastramento biométrico sequer apresenta tal justificativa, o que poderia ser facilmente comprovado com base em estatísticas de processos judiciais que questionem a legitimidade do pleito, sob tal alegação.

A doutrina eleitoral, por outro lado, é extremamente frágil no enfrentamento da real imprescindibilidade da biometria como mecanismo de redução de fraudes relativas à identidade do eleitor. As poucas referências encontradas são de mero enaltecimento da biometria, suscitando problemas outros quanto à autenticidade eleitoral e à fraude na burla às inelegibilidades constitucionais. O prof. José Jairo Gomes, ao defender o recadastramento biométrico, por exemplo, sustenta que "a implantação da nova tecnologia permite concretizar princípios como veracidade, sinceridade e autenticidade do voto e das eleições, aspirações antigas de todos os sistemas democráticos conhecidos"13. Porém, ao relacionar as fraudes eleitorais,

\footnotetext{
12. RECURSO ADMINISTRATIVO. RECADASTRAMENTO ELEITORAL. COLETA DE DADOS BIOMÉTRICOS E FOTOGRÁFICOS. ADI 4543. Lei 7.444/1985 e Resoluções TSE. FUNDAMENTO LEGAL PARA EXIGÊNCIA DO PROCEDIMENTO BIOMÉTRICO E FOTOGRÁFICO. RECADASTRAMENTO BIOMÉTRICO PARA ASSEGURAR O PROCESSO ELEITORAL PROBO E ISENTO. RECURSO DESPROVIDO.

1. O julgamento liminar da ADI 4543, que suspendeu a eficácia do artigo $5^{\circ}$ da Lei 12.034/2009, não pode ser considerado como fundamentação para dispensar a coleta de dados biométricos e fotográficos no recadastramento eleitoral.

2. O artigo $3^{\circ}$ da Lei 7.444/1985 preceitua que o Tribunal Superior Eleitoral deverá regulamentar o procedimento para recadastramento do eleitorado. Assim, amparado pela lei a Corte Eleitoral editou as Resoluções 22.688/2007, 23.061/2009 e 23.335/2011 que instituíram a obrigatoriedade legal do recadastramento com coleta de dados biométricos e fotográficos.

3. O recadastramento eleitoral com o procedimento da biometria visa assegurar aos eleitores um processo eleitoral isento de fraudes, o que se coaduna perfeitamente com os direitos da personalidade.

4. Recurso desprovido. (TRE/DF - PET no 3681 - Brasília/DF - Resolução no 7569 de 21/05/2014 -

Relator(a) MARIA DE FÁTIMA RAFAEL DE AGUIAR - DJE - Diário de Justiça Eletrônico do TREDF, Tomo 95, Data 23/05/2014, Página 08)
}

13. GOMES, José Jairo. Biometria e controle jurídico-social de fraude eleitoral. In: Estudos Eleitorais, Brasília: TSE, v. 6, n. 3, set./dez.2011, p. 96. 
relembra a votação em cédulas como problema superado e elenca as manifestações fraudulentas hodiernamente verificadas:

a) transferência de domicílio eleitoral para viabilizar uma candidatura ou um terceiro mandato - é frequente no cado de prefeitos de cidades continguas;

b) dissolução do casamento para desincompatibilizar o conjuge e/ou parentes. (...)

c) fraude ao artigo $1^{\circ}$, I, "g", da Lei Complementar 64/90, com a revogaçãoo posterior de ato legislativo que reprovou as contas prestadas pelo candidato relativamente à sua gestão; d) pedido de registro de candidato inelegível e sua substituição às vésperas do pleito;

e) transferência fraudulenta de eleitores.

Portanto, como se constata, nenhuma das vicissitudes apontadas pelos doutrinadores ou pela própria Justiça Eleitoral diz respeito a equívocos na identificação do eleitor no momento da votação. Então, vale questionar se as alegadas fraudes à identidade do eleitor são em quantidade e gravidade que justifiquem não só o esforço, inclusive financeiro, mas a mitigação do direito do cidadão à intimidade, inclusive com o compartilhamento de seus dados com um sistema gerenciado pela Polícia Federal e polícias estaduais e que tem por objetivo identificação de pessoas suspeitas da prática de crimes sob a investigação policial?

Se a biometria é apontada como solução contra fraude à identidade do eleitor, deveria impedir aquele que não tivesse seus dados confirmados no exame biométrico realizado no momento da votação. Ao contrário, sendo o direito ao voto garantia constitucional máxima da soberania popular, a Justiça Eleitoral não pode restringi-lo ao eleitor que conseguir demonstrar sua identidade por outros meios que não o biométrico, haja vista a possibilidade de falhas nesse sistema, decorrentes de problemas tecnológicos, como na coleta da assinatura digital, ou por impossibilidade de leitura das informações datiloscópicas do eleitor, que podem ser "apagadas" com a prática de determinadas atividades laborais manuais ou em decorrência de acidentes como cortes ou queimaduras, por exemplo. Nesses casos, a própria Resolução TSE n. 23.335/2011, em seu artigo 17, destaca a impossibilidade de impedimento ao exercício do voto, devendo o eleitor votar e, se necessário, ser posteriormente convocado para a regularização das pendências encontradas.

Portanto, a biometria, ao invés de afastar a possibilidade de fraude na identificação do eleitor, impedindo que alguém vote por outro - o que nem mesmo compreende-se como o maior problema de legitimidade do pleito, entre os existentes -, servirá mais aos fins de controle estatal e de vigilância do que aos democráticos, na medida em que a obrigatoriedade do alistamento eleitoral e a consequente abrangência do cadastramento de eleitores em todo o território nacional permite, conforme ressaltado pela Justiça Eleitoral, que "o maior banco de dados de imagens de impressão digital existente no mundo" esteja disponível às policias federal e civil brasileiras, para uso nas investigações criminais. 


\section{Conclusão}

O advento da biopolítica propiciou o surgimento da ideia de população não mais como um dado primitivo - conjunto de seres humanos sub-rogados à vontade de um soberano. Mas sim como um objeto técnico-político de gestão governamental, no sentido de uma massa homogênea sujeita a variados fenômenos catalogados e analisados pelo Estado para fins de controle.

A partir da ideia da biopolítica, constitui-se a população como correlata das técnicas de poder. Não mais se dá o seu exercício pela vontade do soberano, mas em face do governo, da arte de governar.

Instrumentalizar a administração estatal com mecanismos de controle passou a ser um importante campo de atuação para intervenção do poder. Dessa forma, tem-se o início com o dispositivo disciplinar baseado na vigilância de corpos individuais, em ambientes fechados tais quais presídios, hospitais e escolas -, ordenados segundo a concepção da autonomia da consciência. Isso se aproxima do modelo panóptico, segundo o qual se sabe que é visto, mas não se vê o guardião.

Do modelo de vigilância cerrada, direciona-se ao campo da vigilância à distância. Não mais com o intuito de domesticar corpos, mas no de promover segurança, sem prejuízo do dispositivo disciplinar. A vigilância é cumulativa, apenas agregando em seu desenvolvimento novos elementos facilitadores.

O avanço tecnológico, sobretudo no campo da comunicação, especialmente da informática e da biometria, fez vibrar o modelo panóptico para além das fronteiras delimitadas por muros. Disso resultou o alcance ao campo da virtualidade, um mundo imaterial que proporciona vigiar à distância, ver sem que se saiba estar sendo visto. A dissociação entre o elemento corpo e a vigilância que se exerce sobre ele.

Nesse cerne, a tecnologia empregada na identificação biométrica individual de pessoas, feita através da coleta de impressóes digitais, permite construir um banco de dados, apto a mapear indivíduos a partir de sinais pessoais armazenados em um sistema que possibilita a oferta de variadas informações, as quais resultarão na formação de um catálogo, realizável conforme o objetivo a que se propôs ou, por reflexo, atingir campos alheios àquele objeto inicial.

$\mathrm{O}$ atual recadastramento de cidadãos realizado pela Justiça Eleitoral é obrigatório e o não comparecimento do cidadão ensejará a sua exclusão do cadastro de eleitores, com todas as consequências daí decorrentes, haja visto a obrigatoriedade do alistamento eleitoral. Portanto, todos os cidadãos são obrigados a fornecerem suas impressões digitais para fins de identificação biométrica por ocasião do pleito eleitoral. A finalidade de tal procedimento, prima facie, seria a de impedir ou revelar eventuais fraudes durante o processo de votação, no sentido de prevenir, evitar, que pessoas compareçam à votação se substituindo ao verdadeiro eleitor, votando por ele dentro de um esquema de favorecimento a determinado candidato ou grupo político. Ou seja, aparentemente, o que se busca com o cadastro biométrico de eleitores é afastar a possibilidade de fraude no momento da votação, garantindo-se que o cidadão que comparece à seção eleitoral para votar, seja exatamente aquele eleitor cadastrado como membro daquele colégio de eleitores.

Porém, na medida em que se possibilita o compartilhamento dos dados do Sistema Eleitoral com o Sistema Automatizado de Identificação de Impressões Digitais - AFIS, quebra-se a unicidade daquele, e os seus dados espalham-se para o território do processo penal regido por garantias constitucionais, dentre as quais, a presunção da inocência, corolário do sistema acusa- 
tório. E essa unicidade ficará a cargo do Sistema Automatizado de identificação de Impressões Digitais - AFIS com sede no Instituto Nacional de Identificação - INI e utilizado pelas polícias federal e estaduais para identificação de pessoas envolvidas com práticas delituosas.

Adotando essa configuração, está-se diante do denominado modelo de segurança cidadã que, em nome de um pretenso controle dos riscos da sociedade pós-industrial, espreita e desrespeita as bases do estado democrático. Isso porque viola a soberania individual.

Pode-se afirmar, então, que o recadastramento biométrico compulsório, nessa configuração e com as características aqui apresentadas, constitui um mecanismo de controle criminal invisível, posto que consistente em verdadeira produção antecipada da prova, sem que o indivíduo (o cidadão, o eleitor) se dê conta de que aqueles dados que está fornecendo de forma compulsória poderão servir de substrato probatório em matéria criminal. Isso representa uma espécie de pós-panóptico ou panóptico contemporâneo: a vigilância imposta a todos os eleitores brasileiros.

\section{Referências}

BAUMAN, Zygmunt. Vigilância líquida. Zahar, Rio de Janeiro, 2013.

CALLEGARI, Luis André; WERMUTH, Maiquel Ângelo Dezordi. Sistema penal e política criminal. Livraria do Advogado, Porto Alegre, 2010.

FOUCAULT, Michel. Segurança, território, população. Martins Fontes, São Paulo, 2009.

FOUCAULT, Michel. Vigiar e punir. 40ª ed. Ed. Vozes, Petrópolis, 2012.

GOMES, José Jairo. Biometria e controle jurídico-social de fraude eleitoral. In: Estudos Eleitorais, Brasília: TSE, v. 6, n. 3, p. 93-101, set./dez.2011.

ORWELL, George. 1984. São Paulo: Companhia das Letras, 2009.

RIPOLLÉS, José Luis Diez. La política criminal em la encrucijada. Editorial B de f, Julio César Faira Editor, Montevideo - Buenos Aires, 2007.

TRIBUNAL DE CONTAS DA UNIÃO (TCU). Brasília, 2015. Disponível emะ www.tcu. gov.br. Acesso em 03.05.2015.

TRIBUNAL SUPERIOR ELEITORAL (TSE). Brasília, 2015. Disponível em: www.tse. jus.br. Acesso em 03.05.2015. 
Recebido em: $10 / 11 / 2015$

Aceito em: 02/12/2015

\section{Como citar}

VILLA, Eugênia Nogueira do Rêgo Monteiro; NUNES, Geórgia Ferreira Martins; COELHO, Margarete de Castro. Identificação eleitoral biométrica no Brasil: retorno ao mecanismo panóptico. Ballot. Rio de Janeiro: UERJ. Volume 1 Número 2 Setembro/Dezembro 2015. pp. 162 177. Disponível em: [http://www.e-publicacoes.uerj.br/index.php/ballot]

\section{c) (1) (3)}

A Revista Ballot está licenciada sob uma licença Creative Commons Atribuição - Não Comercial - Compartilha Igual 3.0 Não Adaptada. 